\title{
Shear strength performance of marine sediments stabilized using cement, lime and fly ash \author{
Takeshi Katsumi ${ }^{\mathrm{e}}$
} \\ Ana Paula Furlan ${ }^{\mathrm{a}}$, Andry Razakamanantsoa ${ }^{\mathrm{b}, *}$, Harifidy Ranaivomanana $^{\mathrm{c}}$, Daniel Levacher ${ }^{\mathrm{d}}$,
}

\author{
a University of Sao Paolo, Dept of Transportation Engineering, Sao Carlos, Brazil \\ b IFSTTAR, GERS, GMG, F44344 CS4 Bouguenais, France \\ ${ }^{\mathrm{c}}$ LUNAM University, GeM, UMR6183, F-44606 St Nazaire, France \\ d University of Normandy, LM2C, UMR6143, F-14000 Caen, France \\ e Kyoto University, Graduate School of Global Environmental Studies, Sakyo, Kyoto 606-8501, Japan
}

\begin{abstract}
The combined effects of the chemical stabilization of sediments using lime, cement and fly ash on the sediment shear strength behavior are studied for geotechnical purposes. An elemental analysis is carried out to examine the chemical aspects of stabilized sediments resulting from a series of chemical reactions. Direct shear strength measurements are performed to investigate shear strength improvements and stress-strain behavior of mix samples. A statistical analysis using the principal component analysis and the ANOVA (ANalysis Of Variance) method is also conducted to examine the correlation between cohesion and elemental ratio resulting from the chemical reactions. The analysis of the principal components suggests that $\mathrm{Ca}$ and $\mathrm{Si}$ and $\mathrm{Al}$ and $\mathrm{K}$ have greater impact on cohesion than the other elements. However, the ANOVA method reveals that the elemental ratios of $\mathrm{Si}, \mathrm{Al}$ and $\mathrm{Ca}$ produce less impact on the sediment overall gain in cohesion at 28 days of curing. These results demonstrate that the gain in cohesion mostly depends on some other physical parameters, which need to be yet examined. The prediction equation of the cohesion indicates each elemental component gain weight on the overall cohesion gain resulting from the chemical reactions. In short, the considered equation still needs to be refined, notably in terms of performing further laboratory testing.
\end{abstract}

\section{Introduction}

The production of dredged sediments in France is about thirtyfive to forty million cubic meters annually. $90 \%$ of the dredged sediments are discharged into the sea and might cause a long-term

\footnotetext{
* Corresponding author.

E-mail addresses: andry.razakamanantsoa@ifsttar.fr, andryrico@yahoo.fr (A. Razakamanantsoa).
}

change of the marine environment with significant impact on aquatic fauna and flora.

The possibility to reuse dredged sediments for road and building construction has already been studied by many authors $[11,32,3,21]$. However, several fundamental questions remain and need to be clarified. The present study is conducted to analyze gain in shear strength of dredged sediments combined with fly ash and hydraulic binders. Dredged sediments in their natural state lack the strength, the dimensional stability and the durability required for geotechnical materials used for building and road construction. 
Nevertheless, these inherent deficiencies may be overcome through stabilization by mechanical compaction and addition of chemical stabilizer agents such as lime, cement or fly ash and other type of binders. The technique that modifies the weak characteristics and properties of soil is called soil stabilization. According to Ingles and Metcalf [13], soil strength and compressibility can be improved by physical or chemical stabilization. In physical stabilization, the characteristics and properties improve thanks to soil densification by the addition of other soils with different grain size distribution or by applying higher compaction rate. On the other hand, in chemical stabilization, the soil structure changes thanks to the chemical interactions between soil particles and chemical additives. Little and Nair [18] have demonstrated that soil stiffness, workability and swell characteristics become appropriate when active compounds are added.

The most common additives used for chemical stabilization are lime and ordinary Portland cement. In many countries, lime is recommended to stabilize clayey soils and clays because of a texture change and a plasticity reduction due to the chemical interactions between soil and lime take place. Lime is the result of the calcination of limestone and/or carbonate rocks. According to Thompson [33], the chemical reaction between lime and soil starts immediately after mixing and continues long after. Lime chemical reactions can be divided into four categories: cation exchange, flocculation and agglomeration, carbonation and pozzolanic reactions. Adding lime to soil increases free calcium cation, which might then replace weaker metallic cations adsorbed in colloidal surfaces. These reactions reduce DDL (Diffuse Double Layer) size in clay particles, resulting in a closer arrangement of particles, i.e., flocculation increases $[33,35,20]$. Pozzolanic reactions take place slowly and occur between soil silica and/or alumina in a favorable environment $\mathrm{pH}$ (about 12), forming cementitious compounds like hydrated calcium silicates $(\mathrm{CSH})$ and aluminates (CAH).

Portland cement is often used for the chemical stabilization of granular soils. Walker [37] proposes a systematic investigation of the properties of cement stabilized soils and demonstrates that Unconfined Compressive Strength (UCS) increases with the cement amount increase but is hindered by a clay content with a plasticity index (PI) higher than 15. Cement hydration produces four typical compounds: tricalcium silicate (C3S), dicalcium silicate (C2S), tricalcium aluminate $(\mathrm{C} 3 \mathrm{~A})$ and tetracalcium iron-aluminate (C4AF). Curing time and cement amount are responsible for the improvement in the soil-cement properties (i.e., increase in cohesion, bearing capacity, unconfined compression and tensile strength) $[28,30,27]$. Huang et al. [12] address the problem of the cement bonding strength of stabilized dredged materials after crushing and compaction. It appears that the strength of a stabilized dredged material decreases when it is crushed and compacted. The stabilized dredged material structure is destroyed by crushing and a new soil body (or structure) is formed by the compaction effort. This result shows that the structure of stabilized dredged materials is driven by the cement hydration effect.

In the last decades, fly ash has been successfully used as soil additive as well. Fly ash is a byproduct of coal-fired electrical power plants and contains different mineral compounds such as: silicon dioxide $\left(\mathrm{SiO}_{2}\right)$, aluminum oxide $\left(\mathrm{Al}_{2} \mathrm{O}_{3}\right)$ and calcium oxide $(\mathrm{CaO})$. Replacing cement by fly ash could dramatically reduce carbon dioxide emissions from the cement industry. Specifically, the pozzolanic addition of waste byproducts such as fly ash or paper sludge ash are considered to be environmentally friendly and sustainable [36], Goni et al. [8], Ferrandiz-Mas et al. [6]. Fly ash exhibits pozzolanic behavior, which can vary depending on original coal and burning processes. Generally, fly ash is classified in C or F categories. C fly ash has a high CaO content (about 20\%) that induces some pozzolanic reactions and self-cementing properties.
In $\mathrm{F}$ fly ash, the $\mathrm{CaO}$ content is lower (about 7\%) and, thus, only the pozzolanic reactions occur. To ensure self-cementing in F fly ash, quicklime, hydrated lime and/or Portland cement are added $[23,19]$. Erdal [4] proposes an evaluation of the effects of the addition of class C fly ash, lime and cement on expansive soil. The results show that the addition of $20 \%$ fly ash decreases the swelling potential to nearly the swelling potential obtained with an $8 \%$ lime addition. With the addition of $20 \%$ to $25 \%$ fly ash, there is only a slight decrease in the swelling potential of expansive soils, indicating that the optimum fly ash content is around $20 \%$. Li and Benson [17] also confirm the mechanical performance improvement of road-surface gravel and recycled asphalt pavement (RAP) stabilized using fly ash. Kang et al. [15] have shown that the addition of lime kiln dust and fly ash in soft clays enhances performances, as demonstrated by the increased specific gravity, unconfined compression strength (UCS) and resilient modulus (RM). They conclude that the long-term strength gain can be attributed to pozzolanic reactions occurring with the slow consumption of $\mathrm{Ca}(\mathrm{OH})_{2}$ and short-term strength gain to cation exchange. Trivalent and bivalent cations $\left(\mathrm{Al}^{3+}\right.$ and $\mathrm{Ca}^{2+}$ ) found in fly ash are attracted by the clay particles through cation exchange and replace lower valence cation $\left(\mathrm{H}^{+}, \mathrm{Na}^{+}, \mathrm{K}^{+}\right)$.

The improvement of soil properties by chemical stabilization also depends on the (i) soil material characteristics like soil particle size, chemical composition, ion content in pore water, organic matter and (ii) stabilizer material such as stabilizer amount and water/ stabilizer ratio, (iii) mixture design and (iv) on the treatment conditions such as curing time and special treatments corresponding to each local environment.

The literature review for this paper reveals that soil strength improvement is mainly addressed through unconfined compressive testing. This is because soil overall strength can thus be measured easily and at low cost. However, little research is focusing on the strength gain due to shear strength improvement. Sediment shear properties subjected to chemical stabilization are also relevant because shear strength is a key parameter for geotechnical applications and design such as dyke or dam. The objective of the present study is to examine lime, cement and fly ash effects on the improvement of the mechanical characteristics of stabilized sediments using direct shear testing and elemental analysis of stabilized sediment samples. In addition, a statistical analysis is conducted to determine the correlation between the elemental mineral components and cohesion gain.

\section{Materials and methods}

The Dredged Sediments (DS) from the la Baule le Pouliguen Harbor are characterized according to the French recommendations for embankments and pavement constructionGuide des Terrassements Routier [9] . The results show that the present dredged sediment can be classified as silt clayey with liquidity and plasticity limits equals to $55 \%$ and $41 \%$, respectively, and a plasticity index of $14 \%$ (Table 1 ).

Table 1

Geotechnical properties of the marine sediment.

\begin{tabular}{ll} 
Sand $(>63 \mu \mathrm{m}),(\%)$ & 36 \\
Silt $(2-63 \mu \mathrm{m}),(\%)$ & 31.5 \\
Clay $(<2 \mu \mathrm{m}),(\%)$ & 32.5 \\
Initial water content (\%) & 153 \\
Methylene blue value & 2.75 \\
Specific gravity $\left(\mathrm{Mg} / \mathrm{m}^{3}\right)$ & 2.7 \\
Liquid limit LL (\%) & 55 \\
Plasticity limit PL (\%) & 41 \\
pH & 8.5 \\
Conductivity (ms/cm) & 11.5 \\
Salinity (g/kg) & 6.7 \\
Total dissolved solids (g/l) & 6.4 \\
Organic content (\%) & 12.1 \\
Carbonate content $(\%)$ & 26 \\
\hline
\end{tabular}


Table 2

Portland cement properties.

\begin{tabular}{ll} 
Clinker content & $65-79 \%$ \\
$(\mathrm{CaO})_{3}\left(\mathrm{Al}_{2} \mathrm{O}_{3}\right)$ & $7 \%$ \\
$(\mathrm{CaO})_{3}\left(\mathrm{SiO}_{2}\right)$ & $66 \%$ \\
$(\mathrm{CaO})_{2}\left(\mathrm{SiO}_{2}\right)$ & $10 \%$ \\
Main natural composite & Limestone with total \\
& organic material $\mathrm{C}<0,20 \%$ in mass \\
Short term strength & $32.5 \mathrm{Mpa}$ \\
\hline
\end{tabular}

Table 3

Binder chemical compounds.

\begin{tabular}{llll}
\hline Compound (\%) & Cement & Lime & Fly ash \\
\hline $\mathrm{CaO}$ & 76.9 & 97.2 & 8.52 (total) \\
& & & 0.90 (free) \\
$\mathrm{SiO}_{2}$ & 11.7 & 0.7 & 47.36 \\
$\mathrm{Fe}_{2} \mathrm{O}_{3}$ & 3.9 & 0.5 & 7.09 \\
$\mathrm{SO}_{3}$ & 2.7 & 0.1 & 4.02 \\
$\mathrm{Al}_{2} \mathrm{O}_{3}$ & 2.4 & 0.3 & 21.63 \\
$\mathrm{~K}_{2} \mathrm{O}$ & 1.2 & 0.2 & 4.35 \\
$\mathrm{MgO}$ & 0.6 & 0.7 & 3.32 \\
$\mathrm{TiO}$ & 0.3 & - & - \\
$\mathrm{MnO}$ & 0.1 & 0.1 & 0.62 \\
\hline
\end{tabular}

Table 4

Experimental mix samples.

\begin{tabular}{lllll}
\hline Mixtures & Sediment-S (\%) & Lime-L (\%) & Cement-C (\%) & Fly ash-FA (\%) \\
\hline S & 100 & 0 & 0 & 0 \\
S2L & 98 & 2 & 0 & 0 \\
S7C & 93 & 0 & 7 & 0 \\
S2L7C & 91 & 2 & 7 & 0 \\
S2L9FA & 89 & 2 & 0 & 9 \\
S7C9FA & 84 & 0 & 7 & 9 \\
S2L7C9FA & 82 & 2 & 7 & 9 \\
\hline
\end{tabular}

Organic matter and carbonate contents are about $12.1 \%$ and $26 \%$, respectively. The $\mathrm{pH}$ value is 8.5 . The Proviacal ${ }^{\circledR}$ ST lime is provided by the LHOIST Company in Dugny-sur-Meuse in Lorraine (France). It contains at least $90 \%$ of $\mathrm{CaO}$ and as much as $2 \%$ of MgO. The Portland cement used is CEM II/B-LL 32.5R CE CP2 cement (French Standard) whose main characteristics are listed in Table 2. Sodeline ${ }^{\circledR}$ Fly ash is manufactured by the Emile Huchet plant in Saint-Avold. The chemical composition of the binders is presented in Table 3.

The sediment-binder mixtures are prepared using different binder contents whose choice takes into account economic and environmental approaches. Prior to compaction, the mixtures are wetted to the optimum moisture content and mixed with $2 \%$ of lime, $7 \%$ of Portland cement and $9 \%$ of fly ash, respectively. The different mixture formulation tested are presented in Table 4.

The chemical data analysis is performed on samples obtained from direct shear specimens using the EDX (Energy Dispersive X-ray) system mounted on a FEI Inspect F-50 SEM. Before analysis begins, the samples are covered with aurum to improve reflection and image qualities [7].

Direct shear testing is carried out on the samples compacted to the standard Proctor optimum characteristics [24] and cured during 7 and 28 days at a laboratory temperature of $20^{\circ} \mathrm{C}$. All the tests are performed in drained conditions according to [25].

The pore size distribution measurements are carried out using Mercury Intrusion porosimetry testing (MIP). Some $1-\mathrm{cm}^{3}$ cubic samples are extracted from direct shear specimens. To retain the structure of the soil samples, the cube-samples are frozen during $24 \mathrm{~h}$ and dried by sublimation prior to MIP testing. This procedure ensures the inhibition of the hydration process by sublimation of the water and retains the microstructure.

\section{Results and analysis}

\subsection{Elemental analysis}

The results of the elemental analysis performed on chemically stabilized marine sediment using EDX are discussed. Different dry weight percentages of chemical binders (cement, lime and fly ash) are added to marine sediment dredged from la Baule le Pouliguen harbor (France). This treatment aims to stabilize sediments because marine sediments are typically very soft because of high water salt and organic matter contents. The chemical analysis of the stabilized sediments is therefore essential because chemical phenomena affect their mechanical behavior, in particular the UCS. The composition of the different mixtures prepared is given in Table 4. The water content is adjusted to the optimum water content.

The purpose of the elemental analysis is to investigate elemental composition evolution in the stabilized samples. The elemental composition, indeed, is considered to be strongly linked to the mechanical behavior of the stabilized sediment. The main factors to be taken into consideration for the elemental evolution of stabilized sediment found in the literature are specified in Table 5.

The elemental composition of a stabilized sample is governed by the elemental composition of both sediment and chemical binders and by the chemical reactions.

The carbon element ratio in stabilized sediments is generally related to the amount of organic matter content of the sediment (Table 1). Although the $\mathrm{CaCO}_{3}$ precipitation affects the carbon ratio to some extent Fernandez et al. [5], the effect remains relatively weak because the samples are sealed during the curing period. The oxygen ratio in stabilized soils is highly dependent on the amount of metal oxide content of the sediment and of the chemical binders. The $\mathrm{O}$ ratio in the sediment is increased by some chemical reactions like hydration [26] and $\mathrm{CaCO}_{3}$ precipitation and decreased by the pozzolanic reaction [37] and the decomposition of organic matter within sediment [29]. $\mathrm{Na}$ and $\mathrm{Cl}$ found in the samples are salt derivatives naturally contained in the sediment [34]. Salty- soil is problematic because $\mathrm{Cl}_{2}^{-}$affects negatively cement stabilization of soils [38]. The Ca ratio in sediment increases when adding chemical binders with a high percentage of compounds like lime or cement. During the stabilization process, $\mathrm{Ca}$ is associated with different chemical reactions such as hydration and pozzolanic reactions and $\mathrm{CaCl}_{2}$ and $\mathrm{CaCO}_{3}$ precipitations in the sediment.

Many studies demonstrate that the main source of the sediment strength increase is $\mathrm{C}-\mathrm{S}-\mathrm{H}$ and $\mathrm{C}-\mathrm{A}-\mathrm{H}$ produced by both hydration and pozzolanic reactions [37,1,22,31]. Therefore, knowing the elemental ratios of $\mathrm{Ca}, \mathrm{Si}, \mathrm{Al}$ as a result of a series of chemical reactions to investigate shear strength improvement for each stabilized sample is essential. It should be noted that the direct factor responsible for the strength increase might not be the element ratio of $\mathrm{Ca}, \mathrm{Si}$ or Al but the amount of $\mathrm{C}-\mathrm{S}-\mathrm{H}$ and $\mathrm{C}-\mathrm{A}-\mathrm{H}$ compounds $[38,31]$. Although the determination of the dominant chemical reaction, using the elemental analysis is difficult because many complex reactions are involved, the elemental analysis of stabilized sediment is essential to underline the sediment chemical properties resulting from the chemical reactions.

Figs. 1(a) and 2(a) show the results of the EDX elemental analysis with curing times of 7 days and 28 days, respectively. In order to determine the difference between stabilized samples (S2L, S7C, S2L7C, S7C9FA, S2L9FA, S2L7C9FA) and non-stabilized sample S for both curing times, the normalized elemental concentration (NEC) of each element is defined by dividing an element ratio of the stabilized sample by the element ratio of the non-stabilized sample (Figs. 1(b) and 2(b)). For both curing times, the stabilized samples have a higher $O$ ratio than the non-stabilized sample. This result can be mainly accounted for the hydration reaction of the additive agents. Consequently, all the stabilized samples can be considered to have a higher mechanical strength than $\mathrm{S}$ because many previous studies have highlighted the contribution of hydration products to the mechanical strength improvement [30,39].

As shown in Fig. 1(b), the normalized elemental concentration value of $\mathrm{Ca}$ is greater than 1 for all the stabilized samples. This 
Table 5

Main chemical reactions and resulting chemical components within the stabilized samples.

\begin{tabular}{|c|c|c|c|}
\hline Factor & Chemical reaction results & Notes or observations & $\begin{array}{l}\text { Relevant previous } \\
\text { researches }\end{array}$ \\
\hline Hydration & $\begin{array}{l}\text { Hydration products (tricalcium silicate }(\mathrm{C} 3 \mathrm{~S}) \text {, dicalcium } \\
\text { silicate }(\mathrm{C} 2 \mathrm{~S}) \text {, tricalcium aluminate }(\mathrm{C} 3 \mathrm{~A}) \text { and } \\
\text { tetracalcium iron-aluminate }(\mathrm{C} 4 \mathrm{AF}) \text { ) are formed. }\end{array}$ & $\begin{array}{l}\text { Hydration is affected by the water content in the } \\
\text { mixture }\end{array}$ & {$[4,5,26]$} \\
\hline Pozzolanic reaction & $\begin{array}{l}\text { Hydrated calcium silicates (CSH) and hydrated calcium } \\
\text { aluminates (CAH) are formed }\end{array}$ & Pozzolanic reaction is considered as a long-term reaction & {$[27,38,31,1]$} \\
\hline $\mathrm{CaCO}_{3}$ precipitation & $\mathrm{CaCO}_{3}$ precipitation due to $\mathrm{CO}_{2}$ in the atmosphere & $\begin{array}{l}\text { The process from the diffusion of } \mathrm{CO}_{2} \text { into mixture to the } \\
\text { precipitation of } \mathrm{CaCO}_{3} \text { is slow }\end{array}$ & {$[5,22]$} \\
\hline Salt precipitation & $\mathrm{NaCl}, \mathrm{CaSO}_{4}, \mathrm{MgCl}_{2}, \mathrm{MgSO}_{4}, \mathrm{KCl}$ precipitate & This is mainly due to the evaporation of water & {$[34,2]$} \\
\hline $\begin{array}{l}\text { Decomposition of } \\
\quad \text { organic matters }\end{array}$ & $\mathrm{C}$ and $\mathrm{O}$ are consumed by the decomposition & Oganic matter in the studied is $12 \%$ & [29] \\
\hline
\end{tabular}
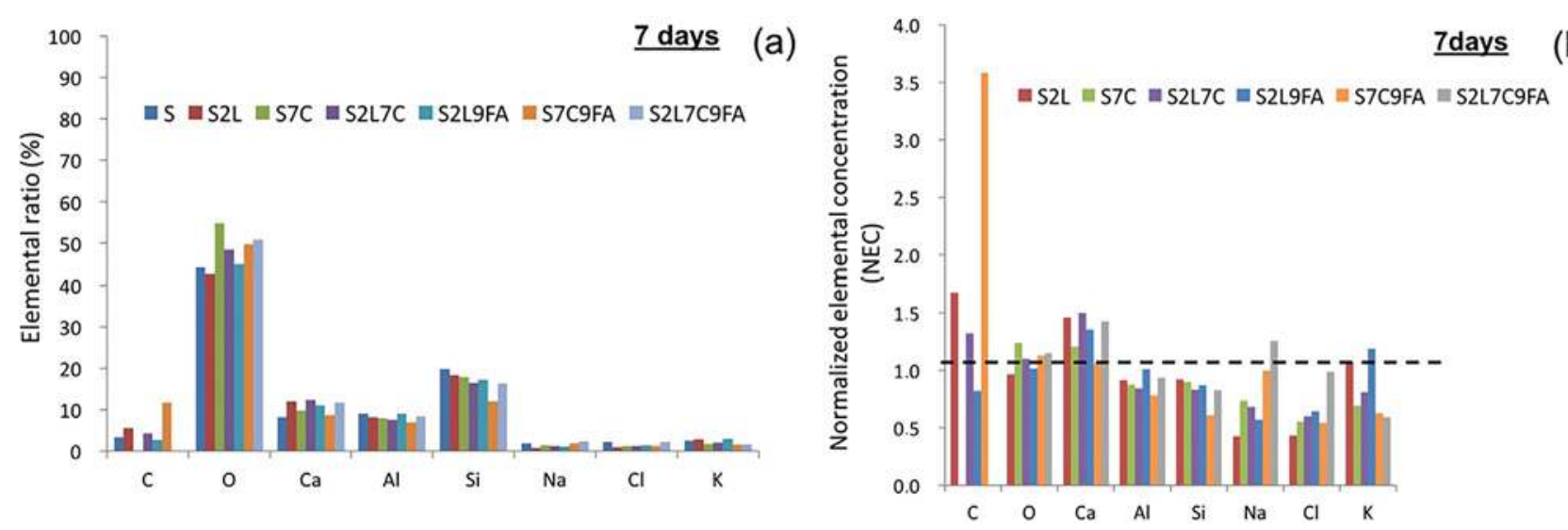

Fig. 1. Mixture elemental components (a) and normalized elemental components (NEC) (b) after 7 days of curing obtained using EDX.
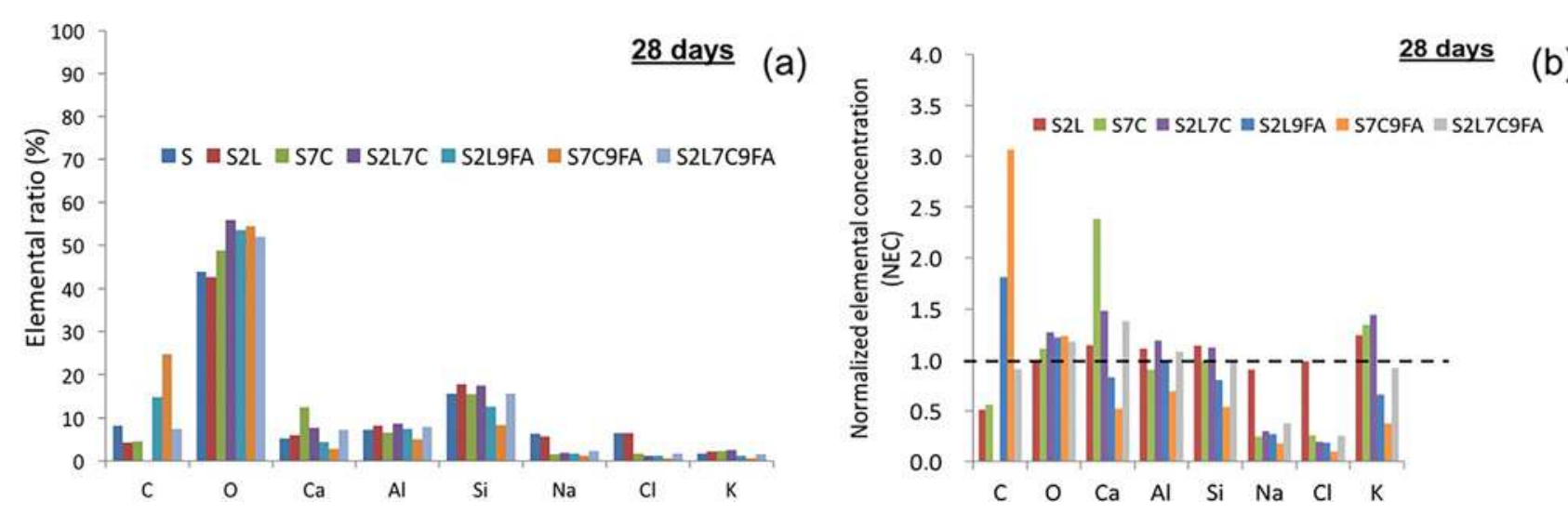

Fig. 2. Mixture elemental components (a) and normalized elemental components (b) after 28 days of curing obtained using EDX.

trend is particularly pronounced in S2L, S2L7C, S2L9FA and S2L7CFA, which confirms the strong influence of a high $\mathrm{CaO}$ content in lime. Kaewmanee et al. [14] have demonstrated that a higher free lime content in fly ash generates early setting and higher compressive strength, especially at early age. In Fig. 1(b), the $\mathrm{C}$ normalized elemental concentration in S7C9FA is extremely high. This may be due to the combined effect of the $\mathrm{CaCO}_{3}$ precipitation and the heterogeneity of organic matter in sediment. The normalized elemental concentrations of $\mathrm{Al}$ and $\mathrm{Si}$ are less than 1 . Hashimoto et al. [10] show that during the first 7 days of the curing period, the hydration reaction dominates while the contribution of the pozzolanic reaction is still relatively small. The normalized elemental concentrations of $\mathrm{Na}, \mathrm{Cl}$ and $\mathrm{K}$ are also lower than 1 because of the dilution effect when binders are added.
Fig. $2 \mathrm{a}$ and $\mathrm{b}$ present the normalized elemental concentrations of the elements for each stabilized sample for the 28-day curing period. The $C$ normalized elemental concentration in S7C9FA is as high as it is after the 7-day curing period. S2L9FA also presents a relatively high $C$ normalized elemental concentration, which can be attributed to the high $\mathrm{CaCO}_{3}$ precipitation rate. Compared with the 7-day curing period, Al and Si show higher normalized elemental concentrations in all the stabilized samples with the exception of S2L9FA and S7C9FA. S2L and S2L7C even have Al and Si normalized elemental concentrations higher than 1. Although S2L9FA and S7C9FA, after the 28-day curing period can be considered to be affected by the pozzolanic reaction, which generally increases $\mathrm{Al}$ and $\mathrm{Si}$ ratios in solids, their $\mathrm{Al}$ and $\mathrm{Si}$ normalized elemental concentrations remain low. The $\mathrm{CaCO}_{3}$ precipitation in pores can be one of 
the reasons for this lower value. In fact, the $\mathrm{C}$ and $\mathrm{O}$ normalized elemental concentrations of S2L9FA and S7C9FA are higher than 1. Moreover, as shown in Figs. $1 \mathrm{a}$ and 2a, the $\mathrm{O}$ ratio is about $50 \%$ in the stabilized samples so that changes in 0 significantly affect $\mathrm{Al}$ and $\mathrm{Si}$ ratios in spite of an $\mathrm{O}$ normalized elemental concentration close to 1 . The normalized elemental concentrations of $\mathrm{Na}$ and $\mathrm{Cl}$ are close to 1 in S2L.

In order to address curing time influence, the normalized elemental concentrations after the 28-day curing period are divided by the normalized elemental concentrations after the 7-day curing period (Fig. 3). This ratio can be used to determine curing time impact, which the normalized elemental concentration cannot do because it is defined to address primarily chemical binder impact. Fig. 3 shows that the $\mathrm{C}$ ratio of S2L9FA, the Ca ratio of S7C, the Al and $\mathrm{Si}$ ratios of S2L7C and the $\mathrm{Na}$ and $\mathrm{Cl}$ ratios of S2L are highly influenced by curing time. The index values of $\mathrm{Na}$ and $\mathrm{Cl}$ for $\mathrm{S} 2 \mathrm{~L}$ are higher than 2 because of the lime evaporation effect. Lime treatments are used to accelerate water evaporation in soil because the exothermic chemical reaction starts immediately after mixing soil and lime [2]. A closer look into $\mathrm{Ca}$ and $\mathrm{Al}$ and $\mathrm{Si}$, considered as chemical strength sources, reveals that the most significant curing time impact on $\mathrm{Al}$ and $\mathrm{Si}$, as observed in S2L7C. S2L7C9FA results, are very similar. Despite high $\mathrm{Al}$ and $\mathrm{Si}$ index values, the Ca index value is lower than 1 in S2L. The Ca index value of S7C is close to 2, which can be attributed to the presence of $76.9 \%$ of $\mathrm{CaO}$ in cement (Table 2). Even if the investigation of the dominant chemical reactions through the elemental analysis alone is somewhat limited, the elemental results can be discussed by comparing them with other test results like shear strength.

\subsection{Shear strength and structural fabric}

\subsubsection{Evolution of shear strength using binders}

Friction angle and cohesion results of direct shear testing are summarized in Table 6. $30-\mathrm{kPa}, 90-\mathrm{kPa}$ and $150-\mathrm{kPa}$ normal stresses, respectively, have been applied on the mix samples after 7 and

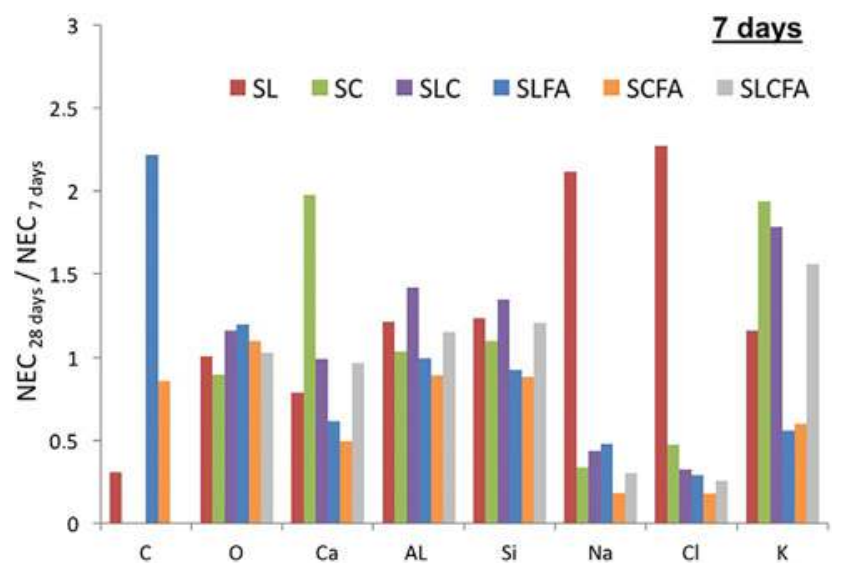

Fig. 3. Curing time effect of time (NEC with 28 days of curing divided by NEC with 7 days of curing).
28 days of curing. These results show that, after the curing period, cohesion significantly increases in the treated samples. The friction angle increase, on the other hand, is small, even insignificant in S7C and S2L7C9FA.

The analysis of the stress-strain behavior of the different mix samples and the failure envelope is carried out to investigate cohesion and friction angle changes.

Fig. 4 presents the stress-strain behavior of the different mixtures for a 7-day curing period according to the different normal stresses applied (30 kPa, $90 \mathrm{kPa}$ and $150 \mathrm{kPa}$ ). From Fig. 4a-g, the shear stress peak increases and strain at peak shear stress increases with the increase of the normal stress. In Fig. 4(a) and (b), S and SL do not display any notable shear stress peak at a normal stress of $150 \mathrm{kPa}$, which is not the case at a normal stress of $30 \mathrm{kPa}$ where a clear shear stress peak appears. The sample maximum shear strength peak measured when a normal stress of $150 \mathrm{kPa}$ is applied after 7 days of curing ranges between 110.85 and $312.77 \mathrm{kPa}$. The measured shear strength values correspond to sediments treated with lime and with a combination of lime, cement and fly ash, respectively.

In order to compare stress-strain behaviors, Fig. 5 presents the results of the shear tests carried out by applying a normal stress of $150 \mathrm{kPa}$ on the stabilized sediment after 7 days of curing without fly ash (Fig. 5a) and with fly ash (Fig. 5b). The shear strength peak increases when adding chemical binders for all the samples except S2L. It should also be pointed out that S2L7C and S2L7C9FA exhibit brittle behavior whereas S and S2L are ductile. Moreover, S2L7C9FA strain at shear stress peak is lower than the other samples. This can be explained as a result of the increase in $\mathrm{C}-\mathrm{S}-\mathrm{H}$ and $\mathrm{C}-\mathrm{A}-\mathrm{H}$ by hydration process. Both mineral phases then occupy more void spaces and develop strong bonding strength between the soil particles, which causes brittle behavior.

The failure envelopes of the stabilized sediment after 7 and 28 days of curing, expressed by the Coulomb failure criterion, are displayed in Fig. 6a-d, respectively. Fig. 6 shows that the stabilized samples with a 7-day curing period have similar internal friction angle values close to that of $\mathrm{S}$. The cohesion of the stabilized samples is also generally higher than that of the non-stabilized sample S. In Fig. 6a, S2L7C exhibits the highest cohesion value (144 kPa), probably resulting from the combination of the particle aggregation caused by lime and the formation of hydration products, such as $\mathrm{C}-\mathrm{S}-\mathrm{H}$ and $\mathrm{C}-\mathrm{A}-\mathrm{H}$, by cement hydration.

Fig. 6 reveals some higher cohesion values after 28 days of curing Fig. 6c and d) instead of seven (Fig. 6a and b). This can be explained by the long term pozzolanic reaction, which continues for a long period of time and generates more $\mathrm{C}-\mathrm{S}-\mathrm{H}$ and $\mathrm{C}-\mathrm{A}-\mathrm{H}$. The failure curve of S2L after 28 days of curing is very similar to that of $S$ as already observed for the 7-day period. This result, as expected, suggests that $2 \%$ of lime is sufficient to improve the workability of sediments but not enough improve sediment shear strength significantly. The cohesion of S7C increases from $95 \mathrm{kPa}$ with 7 days of curing to $145 \mathrm{kPa}$ with 28 days of curing whereas the cohesion of S2L7C increases from $148 \mathrm{kPa}$ to $181 \mathrm{kPa}$. After 7 days of curing, the effect of fly ash on the cohesion increase is more significant after the addition of cement rather than lime.

Table 6

Friction angle and cohesion obtained by shear testing after 7 and 28 days of curing.

\begin{tabular}{|c|c|c|c|c|c|c|c|c|c|c|c|c|c|c|}
\hline \multirow{2}{*}{$\begin{array}{l}\text { Sample } \\
\text { Curing time (day) }\end{array}$} & \multicolumn{2}{|l|}{$\mathrm{S}$} & \multicolumn{2}{|l|}{ S7C } & \multicolumn{2}{|l|}{$\mathrm{S} 2 \mathrm{~L}$} & \multicolumn{2}{|c|}{ S2L7C } & \multicolumn{2}{|c|}{ S2L9FA } & \multicolumn{2}{|c|}{ S7C9FA } & \multicolumn{2}{|c|}{ S2L7C9FA } \\
\hline & 7 & 28 & 7 & 28 & 7 & 28 & 7 & 28 & 7 & 28 & 7 & 28 & 7 & 28 \\
\hline$\phi\left(^{\circ}\right)$ & 26 & 38 & 34 & 28 & 23 & 28 & 36 & 41 & 28 & 25 & 35 & 36 & 60 & 50 \\
\hline $\mathrm{C}(\mathrm{kPa})$ & 51 & 64 & 95 & 145 & 50 & 145 & 148 & 181 & 119 & 147 & 105 & 144 & 36 & 203 \\
\hline $\mathrm{R}^{2}$ & 1.00 & 0.98 & 0.83 & 0.99 & 0.99 & 0.99 & 0.98 & 0.97 & 1.00 & 0.94 & 0.97 & 0.96 & 0.93 & 0.92 \\
\hline
\end{tabular}



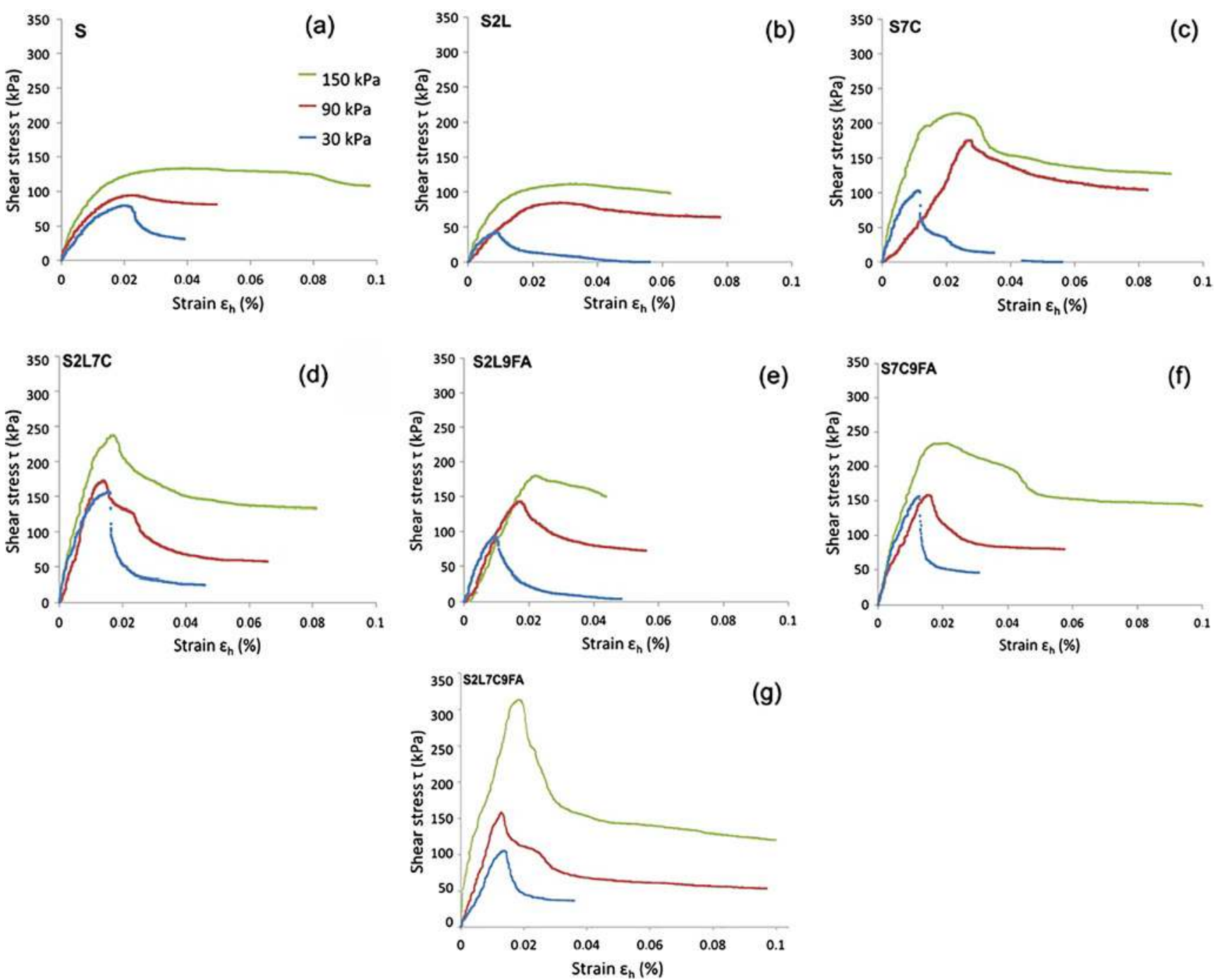

Fig. 4. (a)-(g) Stress strain behavior of S, S2L, S7C, S2L7C, S2L9FA, S7C9FA, S2L7C9FA after 7 days of curing for different normal stresses (30 kPa, $90 \mathrm{kPa}, 150 \mathrm{kPa}$ ), respectively.

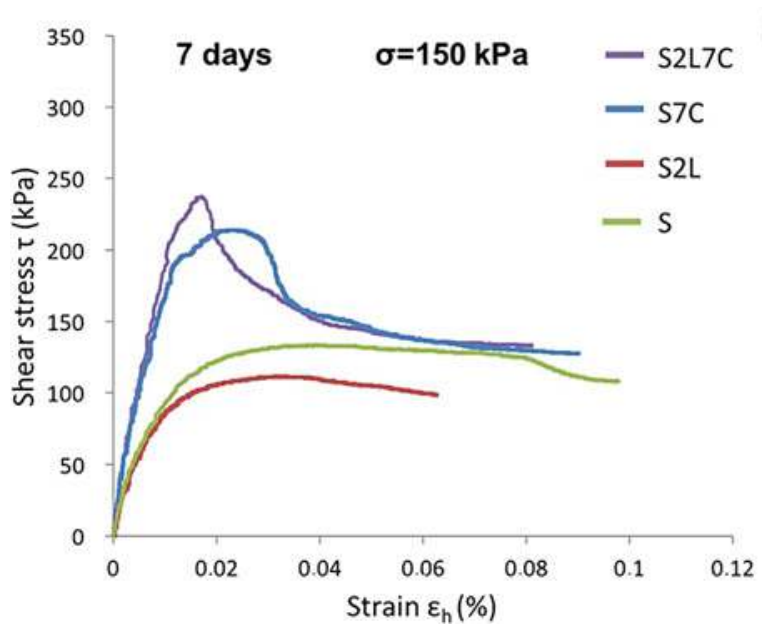

(a)

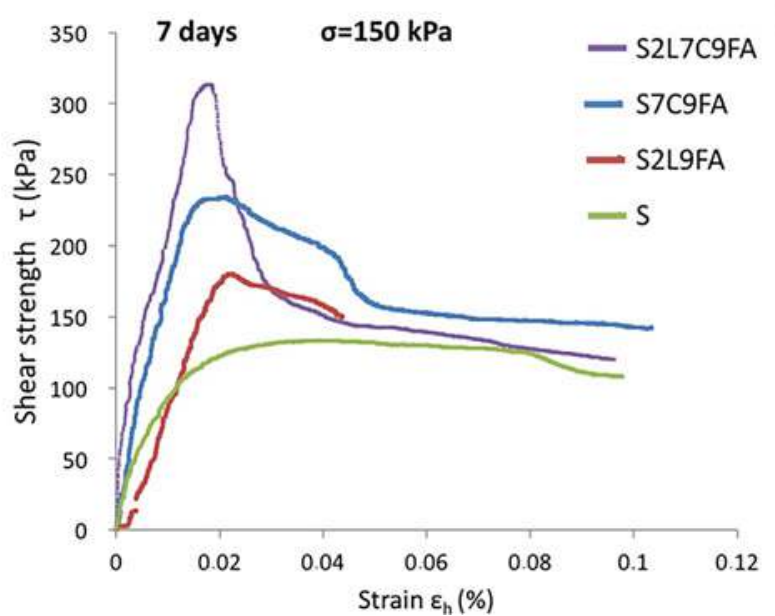

(b)

Fig. 5. Stress strain behavior of the mixtures S, S2L, S7C, S2L7C (a) and S, S2L9FA, S7C9FA, S2L7C9FA (b) after 7 days of curing obtained by direct shear strength.

The cohesion values obtained for S2L, S7C, S2L9FA and S7C9FA are $50 \mathrm{kPa}, 95 \mathrm{kPa}, 119 \mathrm{kPa}$ and $105 \mathrm{kPa}$, respectively, after 7 days of curing.
The same comparison is made for the 28-day curing period and show that the cohesion values resulting from lime and cement addition fall within the range of values obtained by adding fly 

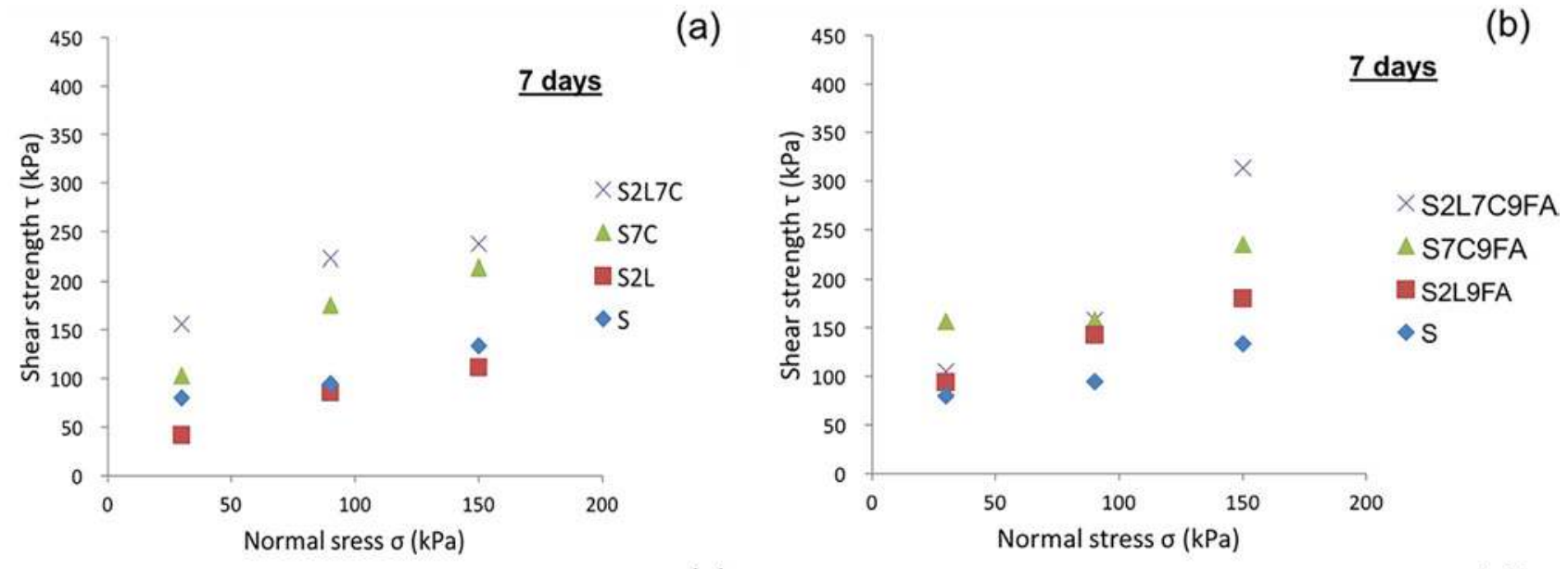

(b)

(c)
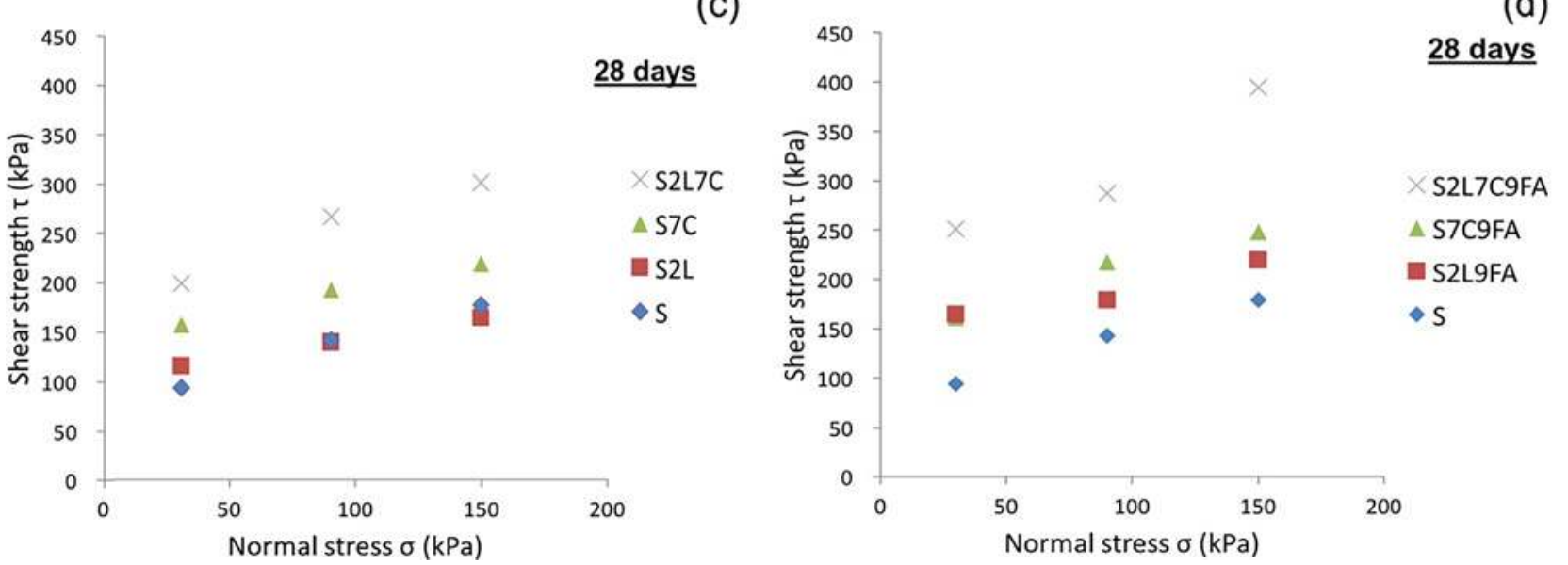

Fig. 6. Failure envelopes of the mixtures S, S2L, S7C, S2L7C, S2L9FA, S7C9FA, S2L7C9FA after 7 (a, b) and 28 (c, d) days of curing obtained by direct shear strength.

ash. Cohesion values after 28 days of curing are equal to $145 \mathrm{kPa}-$ $147 \mathrm{kPa}, \quad 145 \mathrm{kPa}-144 \mathrm{kPa}$ for S2L-S2L9FA, S7C-S7C9FA, respectively.

These results demonstrate that the increase in the cohesion due to curing time is very important between 7 and 28 days: three times higher with lime and 1.5 times higher with cement. The effect of lime and cement on the gain in cohesion is less significant after fly ash addition. The addition of fly ash has a more significant impact on cohesion after 7 days of curing than 28 days.

This result is not consistent with previous literature studies conducted to examine pozzolanic reactions using fly ash. It demonstrates the relevance of the water distribution during curing periods because the effect of the pozzolanic reaction of fly ash is a longer-term effect [1]. The evolution of the hydric effect with curing time is highlighted. The drying process resulting from curing and the chemical hydration of binders increase the development of capillary bridges between the sediment particles. The gain in cohesion is then the result of the combined effect of the capillary bridge increase due to water distribution and of the chemical reactions caused by the fly ash and binder effects.

\subsubsection{Influence of binder addition on sample structural fabric modification}

In order to understand binder addition effect on dredged sediment better, Mercury Intrusion Porosimetry (MIP) testing is carried out. MIP is the predominant method of microstructure characterization through pore size distribution of porous materials. The method consists in injecting mercury into a dried and degassed material. To retain the microstructure, the samples are dried by sublimation after $24 \mathrm{~h}$ of freezing process. The volume of mercury injected corresponds to the cumulative pore volume accessible to mercury. Assuming that the pores are cylindrical, the relationship between the accessible diameter, $\mathrm{d}_{\mathrm{c}}$, of the pores and the mercury injection pressure, $\mathrm{P}$, is expressed by Washburn' law as:

$P=-\frac{4 \sigma_{H g} \cos \theta}{d_{c}}$

where $\sigma_{\mathrm{Hg}}$ is the mercury surface tension $\left(\sigma_{\mathrm{Hg}}=0.485 \mathrm{~N} / \mathrm{m}\right.$ at $25^{\circ} \mathrm{C}$ ) and $\theta$ the contact angle of the meniscus solid/mercury $\left(\theta=130^{\circ}>90^{\circ}\right.$ because mercury is a non-wetting fluid).

The pore size distribution curves after a 7-day curing period are presented in Fig. 7a for the mixtures without fly ash and in Fig. 7b for mixtures with fly ash. Table 7 displays the changes in the mode values related to pore families identified by MIP testing for all the tested mixtures.

First, the dredged sediment pore distribution exhibits two distinct peaks of low intensity associated with macro and micropores, respectively. This result is in good accordance with the typical classification of soil porous structure into two categories according to pore size: small pores (ranging from 2 to $400 \mathrm{~nm}$ in diameter) located within the aggregates and associated with textural porosity, and large pores (ranging from 0.4 to $60 \mu \mathrm{m}$ in diameter) located between the aggregates and associated with structural porosity. The comparison between natural and treated sediments shows that:

- There is no significant evolution in mode values between both materials. However, the S2L mix presents a lower volume of macropores and a larger volume of micropores in comparison 

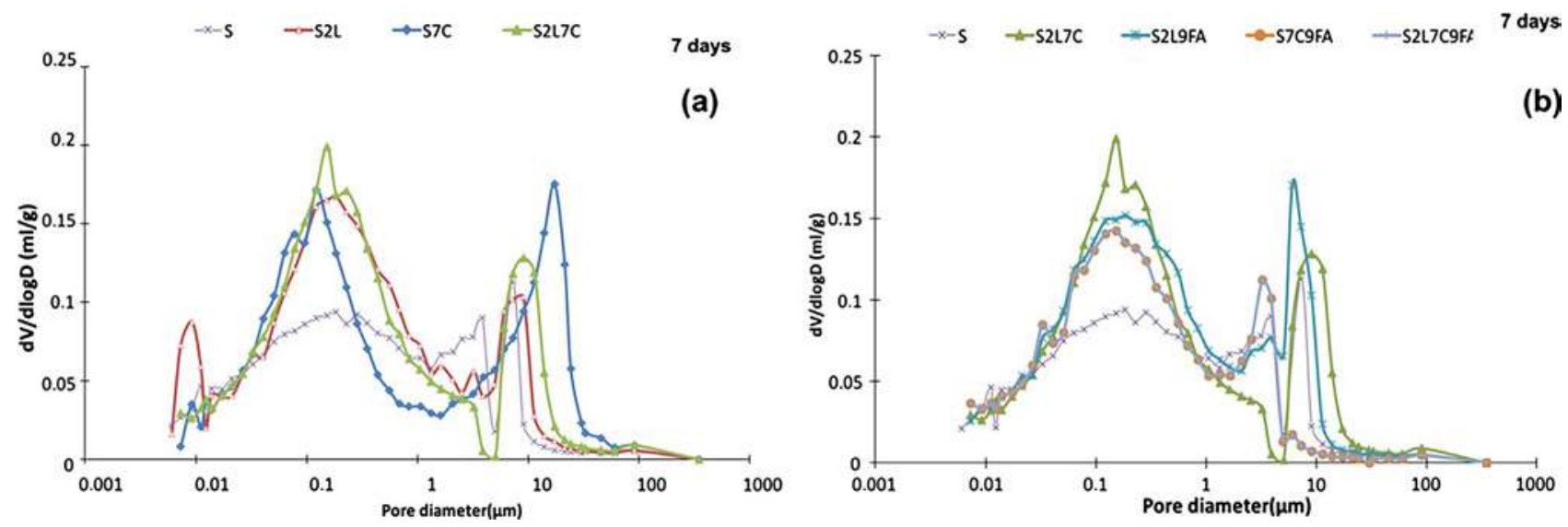

Fig. 7. Pore size distribution of the mixtures without fly ash (S, S2L, S7C, S2L7C) (a) and with fly ash (S2L9FA, S7C9FA, S2L7C9FA) (b) after 7 days of curing.

Table 7

Mode values related to pore families identified by MIP testing.

\begin{tabular}{lll}
\hline & First mode $(\mu \mathrm{m})$ & Second mode $(\mu \mathrm{m})$ \\
\hline S & 0.18 & 7.24 \\
S2L & 0.18 & 9.05 \\
S7C & 0.12 & 17.25 \\
S2L7C & 0.15 & 9.05 \\
S2L9FA & 0.23 & 6.04 \\
S7C9FA & 0.15 & 3.24 \\
S2L7C9FA & 0.18 & 9.07 \\
\hline
\end{tabular}

with natural sediment. This result can be explained by the presence of hydration products (C-S-H, C-A-S-H) within the macropores, which reduce inter-aggregate macro porosity.

- The S7C mix has undergone a significant evolution in mode values particularly as regards macropores accompanied by an increase in volume for both micro and macropores. The large newly formed macropores are the consequences of the cracking phenomenon resulting from the restrained shrinkage of cement hydration products in the presence of soil particles. According to Lemaire et al. [16], the addition of cement to fine soil generates the distribution of cement particles around the aggregates without penetrating them and thus produces stronger links between two adjoining aggregates. These strong links probably affect the cement hydration product shrinkage occurring under restrained conditions. As previously observed in $\mathrm{S} 2 \mathrm{~L}$, the increase in micropore volume can be explained by the presence of hydration products within the macropores resulting in the reduction of inter-aggregate macro porosity.

- The results obtained for S2L7C and S2L are similar in terms of mode values and pore volume for both macro and micropores. This can be explained by the fact that the presence of cement does not affect the microstructure because, as mentioned in Section 2, the porous space is already occupied by the hydration products of lime, introduced in the mix first.

- The presence of fly ash causes the refinement of the pore structure. Indeed, the mixtures containing fly ash (S2L9FA and S7C9FA) present a lower macropore mode value and an increase in both macro-and micropores volumes in comparison with the other mixtures. Pore structure refinement can be attributed to the "filler effect" of the fine fraction of fly ash, which may have filled some pores. It is worth noting that as the fly ash pozzolanic reaction continues, the refinement of the pore structure observed here is similar to cementitious materials.

\subsection{Statistical analysis}

A statistical analysis is conducted to investigate the effect of the elemental constituents on the shear strength of stabilized sediment samples. Calculations are carried out using XL Stat premium. The principal component analysis (PCA) is first conducted to determine the main chemical elements highly correlated with cohesion. The most significant element is deduced from the comparison between the factor axes. Then, a multiple regression analysis is performed to assess the independent effect of $\mathrm{Ca}, \mathrm{Si}, \mathrm{Al}$ ratios as explanatory variables. These variables, indeed, prove to have significant effects on the cohesion of the mix samples deduced from PCA.

The principal component analysis aims to identify the main chemical elements contributing to the increase in stabilized sediment cohesion. Fig. 8a-c display the results of the comparison of the correlations between element component and cohesion obtained by PCA for plans F1-F2, F1-F3, F3-F2, respectively. These results show that $\mathrm{Al}$ and $\mathrm{Si}, \mathrm{Ca}$ and $\mathrm{K}$ are highly correlated with the cohesion in comparison with the other components. These components, indeed, are elements of the gel of C-S-H or C-A-H surrounding the soil particles and considered as the main factors affecting strength gain of sediment using chemical stabilization. Examples are silt [16], and dredged sediments [39].

A multiple regression analysis using the ANOVA (ANalysis Of Variance) method is performed to propose a prediction equation with cohesion as objective variable and values of $\mathrm{Al}, \mathrm{Si}$ and $\mathrm{Ca}$ ratios as explanatory variables. Based on a literature review, the $\mathrm{K}$ element is not considered [31].

In engineering practice, the prediction of shear strength using elemental analysis can help select simple tools for analyzing the relationships between cohesion and chemical reactions taking place during the chemical stabilization of sediments. The solution of this problem is written by Eq. (2) as:

Cohesion $=-30.1+14.6 \times \mathrm{Ca}+73.8 \times \mathrm{Al}-31.5 \times \mathrm{Si}$

$\mathrm{Ca}$ and $\mathrm{Al}$ affect positively the gain in cohesion whereas $\mathrm{Si}$ has negative impact. Fig. 9 presents the correlation between the experimental and the predicted cohesions obtained using Eq. (2). The results show a good estimation of the cohesion although the adjusted $R^{2}$ obtained is 0.45 , which means that only $44.80 \%$ of the experimental cohesion is predicted using the equation.

The probability value (P-value) is 0.23 , which is higher than the significance level of 0.05 . The P-value is a "probability" used to reach at least the same or higher value than actual observed 

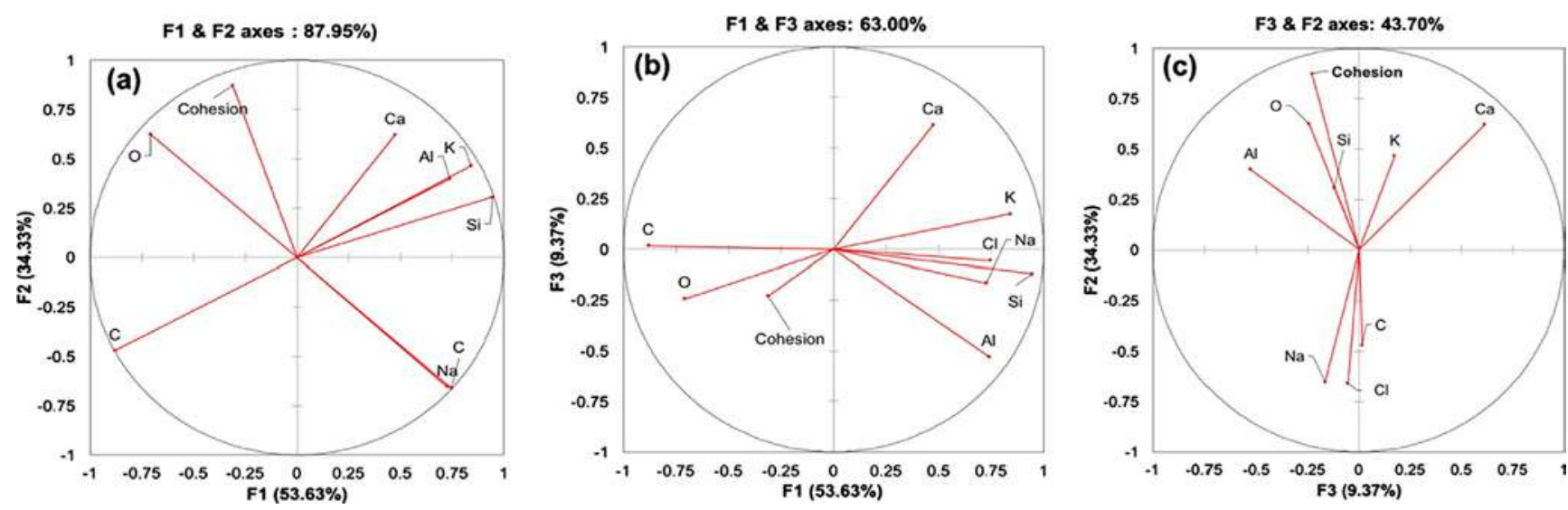

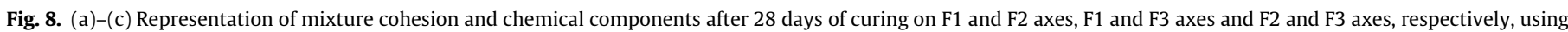
principal component analysis.

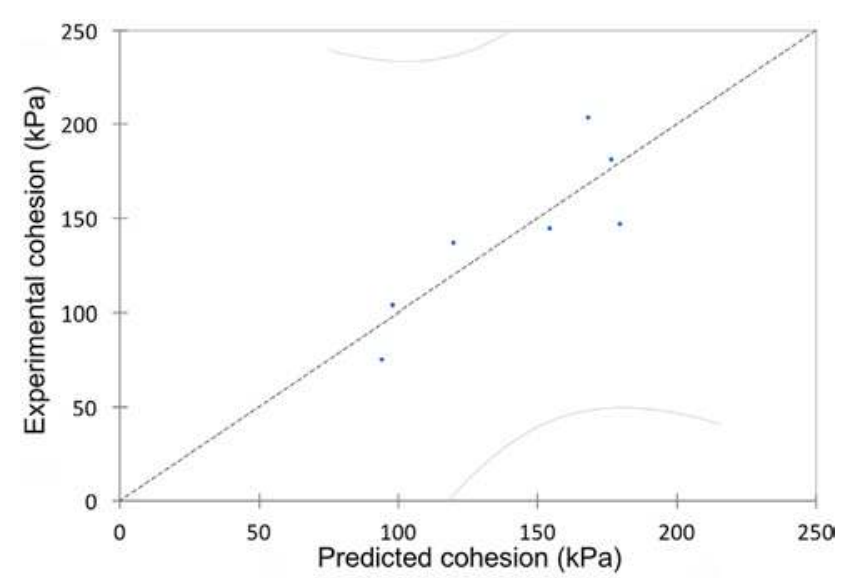

Fig. 9. Correlation between the mixture measured and predicted cohesions after 28 days of curing.

results. It is therefore considered that there is no significant relationship between the objective variable of cohesion and the explanatory variables of $\mathrm{Ca}, \mathrm{Si}$, and $\mathrm{Al}$. The low correlation between cohesion and chemical elements suggests the existence of other mechanisms that control cohesion evolution. The correlation between the factors is underlined but the accuracy of the prediction equation can be further improved through additional research. Table 8 presents the statistical results obtained using ANOVA, which confirms that $\mathrm{Si}$ has the most significant impact on cohesion.

Table 8

Statistical analysis using ANOVA to highlight the effects of $\mathrm{Ca}, \mathrm{Al}$, Si elemental ratios on cohesion.

\begin{tabular}{lllll}
\hline Factors & $\mathrm{F}$ & $\mathrm{P}>\mathrm{F}$ & $\begin{array}{l}\text { Significance } \\
\text { degree of factor } \\
\text { effects on } \\
\text { cohesion }\end{array}$ & $\begin{array}{l}\text { Positive correlation (+) or } \\
\text { negative correlation }(-) \text { on } \\
\text { the value of cohesion }\end{array}$ \\
\hline $\mathrm{Ca}$ & 5.546 & 0.100 & $*$ & + \\
$\mathrm{Al}$ & 6.712 & 0.081 & $* *$ & + \\
$\mathrm{Si}$ & 6.788 & 0.080 & $* *$ & - \\
\hline
\end{tabular}

*: less significant (p-value $<0.15$ ); ${ }^{* *}$ : more significant (p-value $<0.1$ ); ${ }^{* *}+$ : positive correlation; -: negative correlation.

\section{Conclusion}

Opportunity for using dredged sediments combined to hydraulic binders and fly ash as an alternative material for civil engineering is investigated here. The combined effects of the addition of cement, lime and fly ash to sediment samples on properties including elemental component and shear strength are examined. An elemental analysis is performed on the stabilized sediments to highlight the chemical state of the samples after a series of chemical reactions (hydration, pozzolanic reaction and precipitation). Direct shear tests are carried out to demonstrate shear strength improvement using chemical stabilization treatments. The relationship between cohesion and elemental ratio is identified using a statistical analysis including a principal component analysis and a multiple regression analysis.

The elemental analysis results show that the stabilized samples have a higher $\mathrm{O}$ ratio than the non-stabilized sample for both curing times studied ( 7 days and 28 days). This observation can be attributed to the hydration reaction of the additive agents. After 28 days of curing, all the stabilized samples, except S2L9FA and S7C9FA, present higher Al and Si normalized elemental concentrations in comparison with those obtained after 7 days of curing. S2L7C and S2L7C9FA show a similar trend as regards curing time influence. The ratio of the Al ratio in S2L7C or S2L7C9FA to the Al ratio in $S$ increases between 7 days and 28 days of curing. The same trend is observed for Si.

The shear test results demonstrate that binder addition, together with curing time, positively affects cohesion. The gain in cohesion for the treated samples is the result of the coupled effects of chemical binding and capillary bridge enhanced by curing time. The cohesion of all the stabilized samples is generally higher than that of the non-stabilized sample, $\mathrm{S}$. The results also show that the friction angle is less affected and its value remains close to the non-treated sediment one.

The analysis of the pore size distribution of the tested samples reveals that, as expected, the S2L mix exhibits a reduced volume of macropore and an increased volume of micropores compared with natural sediment. S2L7C and S2L behave similarly in terms of mode values and pore volume for both macro and micropores because the porous space is already occupied by the hydration products of lime. The presence of fly ash, moreover, causes a refinement of the pore structure.

The principal component analysis underlines that the ratios of $\mathrm{Ca}, \mathrm{Si}, \mathrm{Al}$ and $\mathrm{K}$ in the mix samples have the strongest correlation with cohesion gain in comparison with the other elements 
considered. However, the multiple regression analysis shows that the correlation between $\mathrm{Ca}, \mathrm{Si}, \mathrm{Al}$ and cohesion has to be coupled with the capillary bridge effect.

Based on these initial findings, the present study demonstrates the feasibility of using waste materials like dredged sediments and fly ash for civil engineering purposes by adding a combination of commonly used hydraulic binders.

\section{Declarations of interest}

\section{None.}

\section{Acknowledgements}

The present study was supported by the National Council for Scientific and Technological Development (CNPq), Brazil within the framework of the Post Doctorial Position at IFSTTAR-NantesFrance (IFSTTAR/DAEI/PMQ/SP/19/08/2014). Special thanks to Takuro AKAMA from Kyoto University for the valuable technical assistance provided during his internship at IFSTTAR Nantes. In collaboration with Caen University (M2C UMR 6143 CNRS).

\section{References}

[1] F.G. Bell, Lime stabilization of clay minerals and soils, Eng. Geol. 42 (4) (1996) 223-237, https://doi.org/10.1016/0013-7952(96)00028-2.

[2] J. Couvidat, M. Benzaazoua, V. Chatain, H. Bouzahzah, Environmental evaluation of dredged sediment submitted to a solidification stabilization process using hydraulic binders, Environ. Sci. Pollut. Res. 23 (17) (2016) 17142-17157, https://doi.org/10.1007/s11356-016-6869-9.

[3] V. Dubois, N.E. Abriak, R. Zentar, G. Ballivy, The use of marine sediments as a pavement base material, Waste Manage. (Oxford) 29 (2) (2009) 774-782, https://doi.org/10.1016/j.wasman.2008.05.004.

[4] C. Erdal, Class C fly ashes for the stabilization of an expansive soil, J. Geotech. Geoenviron. Eng. 568-573 (2001), https://doi.org/10.1061/(ASCE)1090-0241 (2001) 127:7(568).

[5] B.M. Fernandez, S.J.R. Simons, C.D. Hills, P.J. Carey, A review of accelerated carbonation technology in the treatment of cement-based materials and sequestration of CO2, J. Hazard. Mater. 112 (3) (2004) 193-205. 10.1016/j. jhazmat.2004.04.019.

[6] V. Ferrandiz-Mas, T. Bond, E. Garcia-Alcocel, C.R. Cheeseman, Lightweight mortars containing expanded polystyrene and paper sludge ash, Constr. Build. Mater. 61 (2014) 285-292, https://doi.org/10.1016/j.conbuildmat.2014.03.028.

[7] A.P. Furlan, A.R. Razakamanantsoa, Y. Liang, D. Deneele, Feasibility study of chemical stabilization of dredged marine sediment, in: Third Coastal and Maritime Mediterranean Conference, Ferrara, Italia, 2015, pp. 143-148, https://doi.org/10.5150/cmcm.2015.029.

[8] S. Goni, M. Frias, R.V. De La Villa, I. Vegas, Decalcification of activated paper sludge - fly ash-Portland cement blended pastes in pure water, Cem. Concr Compos. 40 (2013) 1-6, https://doi.org/10.1016/j.cemconcomp.2013.04.002.

[9] Guide des Terrassements Routier (GTR), Réalisation des remblais et des couches de forme, in: Technical guide, Fascicule 1, Principe généraux, 2nd Ed, SETRA - LCPC, D 9233-2, 2000, 221p.

[10] T. Hashimoto, Y. Shirane, H. Takahashi, K. Torii, A Consideration on the Mechanisms of improvement in compressive strength of concretes using both classified fine fly ashes and limestone aggregates, J. Soc. Mater. Sci. Jpn. 63 (10) (2014) 694-701, https://doi.org/10.2472/jsms.63.694.

[11] K. Hamer, V. Karius, Brick production with dredged harbor sediments. An industrial scale experiment, Waste Manage. 22 (5) (2002) 521-530, https:// doi.org/10.1016/S0956-053X(01)00048-4.

[12] Y. Huang, W. Zhu, X. Qian, N. Zhang, X. Zhou, Change of mechanical behavior between solidified and remolded solidified dredged materials, Eng. Geol. 119 (3-4) (2011) 112-119, https://doi.org/10.1016/j.enggeo.2011.03.005.

[13] O.G. Ingles, J.B. Metcalf, Soil Stabilization: Principles and Practice, first ed., Butterworths, Melbourne, AU, 1972.

[14] K. Kaewmanee, P. Krammart, T. Sumranwanich, P. Choktaweekarn, S. Tangtermsirikul, Effect of free lime content on properties of cement and fly ash mixtures, Constr. Build. Mater. 38 (2013) 829-836, https://doi.org 10.1016/j.conbuildmat.2012.09.035.

[15] X. Kang, G.C. Kang, K. Chang, L. Ge, Chemically stabilized soft clays for roadbase construction, J. Mater. Civil Eng. ASCE 27 (7) (2015), https://doi.org/ 10.1061/(ASCE)MT.1943-5533.0001156.
[16] K. Lemaire, D. Deneele, S. Bonnet, M. Legret, Effects of lime and cement treatment on the physicochemical, microstructural and mechanical characteristics of a plastic silt, Eng. Geol. 166 (2013) 255-261, https://doi. org/10.1016/j.enggeo.2013.09.012.

[17] L. Li, T.B. Edil, C.H. Benson, Properties of pavement geomaterials stabilized with fly ash, in: World of Coal Ash (WOCA) Conference - May 4-7, 2009 in Lexington, KY, USA, 2009. http://www.flyash.info/.

[18] D.N. Little, S. Nair, Recommended Practice for Stabilization of Subgrade Soils and Base Materials. 57p. Research Report (NCHRP Project 20-07), Texas A\&M University, College Station US, 2009.

[19] D.N. Little, E.H. Males, J.R. Prusinski, B. Stewart, Cementitious Stabilization. 79th Millennium Report Series, Transportation Research Board, Washington, US, 2000 , p. 7.

[20] J. Mallela, H. Quintus, K.L. Smith, in: Consideration of Lime-Stabilized Layers in Mechanistic-Empirical Pavement Design. Final Report Submitted to the National Lime Association, NLA, Arlington, US, 2004, p. 36.

[21] A. Mezencevova, N.N. Yeboah, S.E. Burns, L.F. Kahn, K.E. Kurtis, Utilization of savannah harbor river sediment as the primary raw material in production of fired brick, J. Environ. Manage. 113 (2012) 128-136, https://doi.org/10.1016/ j.jenvman.2012.08.030.

[22] Z. Metelkova, J. Bohac, R. Prikryl, I. Sedlarova, Maturation of loess treated with variable lime admixture: pore space textural evolution and related phase changes, Appl. Clay Sci. (2012), https://doi.org/10.1016/j.clay.2012.03.008.

[23] A. Misra, Stabilization characteristics of clays using class C fly ash, in: Transportation Research Record, Transportation Research Board, Washington, US, 1998, pp. 46-54.

[24] NF P94-093, Soil: Investigation and Testing - Determination of the Compaction Characteristics of a Soil - Standard Proctor Test - Modified Proctor Test. AFNOR, ISSN 0335-3931, 1999.

[25] NF P 94071-1, Soil: Investigation and Testing - Direct Shear Test with Shear Box Apparatus - Part 1: Direct Shear, AFNOR, ISSN 0335-3931, 1994.

[26] F. Pacheco-Torgal, J. Castro-Gomes, S. Jalali, Alkali-activated binders: a review. Part 1. Historical background, terminology, reaction mechanisms and hydration products, Constr. Build. Mater. 22 (7) (2008) 1305-1314, https:// doi.org/10.1016/j.conbuildmat.2007.10.015.

[27] M.S. Pakbaz, R. Alipour, Influence of cement addition on the geotechnical properties of an Iranian clay, Appl. Clay Sci. 67-68 (2012) 1-4, https://doi.org/ 10.1016/j.clay.2012.07.006.

[28] E. Parente, A.B. Parreira, Avaliação do comportamento mecânico de um solo laterítico e de outro não laterítico estabilizados com cimento, Anais do XVI Congresso de Pesquisa e Ensino em Transportes da Associação Nacional de Pesquisa e Ensino em Transportes (ANPET) 1 (2002) 95-107.

[29] K.R. Reddy, W.H. Patrick, Effect of alternate aerobic and anaerobic conditions on redox potential, organic matter decomposition and nitrogen loss in a flooded soil, Soil Biol. Biochem. 7 (2) (1975) 87-94, https://doi.org/10.1016/ 0038-0717(75)90004-8.

[30] F. Sariosseiri, B. Muhunthan, Effect of cement treatment on geotechnical properties of some Washington State soils, Eng. Geol. 104 (1-2) (2009) 119125, https://doi.org/10.1016/j.enggeo.2008.09.003.

[31] N.K. Sharma, S.K. Swain, U.C. Sahoo, Stabilization of a clayey soil with fly ash and lime: a micro level investigation, Geotech. Geol. Eng. (2012), https://doi. org/10.1007/s10706-012-9532-3.

[32] K. Siham, B. Fabrice, N.E. Abriak, P. Degrugilliers, Marine dredged sediments as new materials resource for road construction, Waste Manage. 28 (5) (2008) 919-928, https://doi.org/10.1016/j.wasman.2007.03.027.

[33] M.R. Thompson, Lime reactivity of illinois soils, J. Soil Mech. Found. Division 92 (SM5) (1966) 67-92. Reston, US.

[34] M. Tian, H.T. Zhu, J. Feng, Q.S. Zhao, Evaluation and analysis of underground brine resources in the southern coastal area of Laizhou Bay, IOP Conf. Ser.: Earth Environ. Sci. 39 (2016) 12033, https://doi.org/10.1088/1755-1315/39/1/ 012033.

[35] TRB, Lime Stabilization: Reactions, Properties, Design, and Construction. State of the Art Report 5, Transportation Research Board, Washington, US, 1987, p. 59.

[36] I. Vegas, J.J. Gaitero, J. Urreta, R. Garcia, M. Frias, Aging and durability of ternary cements containing fly ash and activated paper sludge, Constr. Build. Mater. 52 (2014) 253-260, https://doi.org/10.1016/j.conbuildmat.2013.10.070.

[37] P.J. Walker, Strength, durability and shrinkage characteristics of cement stabilised soil blocks, Cem. Concr. Compos. 17 (4) (1995) 301-310, https://doi. org/10.1016/0958-9465(95)00019-9.

[38] H. Xing, X. Yang, C. Xu, G. Ye, Strength characteristics and mechanisms of saltrich soil-cement, Eng. Geol. 103 (1-2) (2009) 33-38, https://doi.org/10.1016/j. enggeo.2008.07.011.

[39] R. Zentar, D. Wang, N.E. Abriak, M. Benzerzour, W. Chen, Utilization of siliceousaluminous fly ash and cement for solidification of marine sediments, Constr. Build. Mater. (2012), https://doi.org/10.1016/j.conbuildmat.2012.04.024. 